\title{
Interaction of $\alpha_{\mathrm{V}} \beta_{3}$ and $\alpha_{\mathrm{V}} \beta_{6}$ Integrins with Human Parechovirus $1^{\nabla}$
}

\author{
Jani Seitsonen, ${ }^{1}$ Petri Susi, ${ }^{2}$ Outi Heikkilä, ${ }^{2}$ Robert S. Sinkovits, ${ }^{3}$ Pasi Laurinmäki, ${ }^{1}$ \\ Timo Hyypiä, ${ }^{2}$ and Sarah J. Butcher ${ }^{1 *}$ \\ Institute of Biotechnology and Department of Biosciences, P.O. Box 65, FIN-00014 University of Helsinki, Helsinki, \\ Finland $^{1}$; Department of Virology, University of Turku, FIN-20520 Turku, Finland ${ }^{2}$; and Department of \\ Chemistry and Biochemistry, University of California, La Jolla, California ${ }^{3}$
}

Received 14 October 2009/Accepted 31 May 2010

\begin{abstract}
Human parechovirus (HPEV) infections are very common in early childhood and can be severe in neonates. It has been shown that integrins are important for cellular infectivity of HPEV1 through experiments using peptide blocking assays and function-blocking antibodies to $\alpha_{V}$ integrins. The interaction of HPEV1 with $\alpha_{V}$ integrins is presumably mediated by a C-terminal RGD motif in the capsid protein VP1. We characterized the binding of integrins $\alpha_{v} \beta_{3}$ and $\alpha_{v} \beta_{6}$ to HPEV1 by biochemical and structural studies. We showed that although HPEV1 bound efficiently to immobilized integrins, $\alpha_{v} \beta_{6}$ bound more efficiently than $\alpha_{v} \beta_{3}$ to immobilized HPEV1. Moreover, soluble $\alpha_{\mathrm{v}} \beta_{6}$, but not $\alpha_{\mathrm{v}} \beta_{3}$, blocked HPEV1 cellular infectivity, indicating that it is a high-affinity receptor for HPEV1. We also showed that HPEV1 binding to integrins in vitro could be partially blocked by RGD peptides. Using electron cryo-microscopy and image reconstruction, we showed that HPEV1 has the typical $T=1$ (pseudo $T=3$ ) organization of a picornavirus. Complexes of HPEV1 and integrins indicated that both integrin footprints reside between the 5-fold and 3-fold symmetry axes. This result does not match the RGD position predicted from the coxsackievirus A9 X-ray structure but is consistent with the predicted location of this motif in the shorter $\mathrm{C}$ terminus found in HPEV1. This first structural characterization of a parechovirus indicates that the differences in receptor binding are due to the amino acid differences in the integrins rather than to significantly different viral footprints.
\end{abstract}

Picornaviruses consist of a positive-sense, single-stranded infectious RNA genome of approximately $7.3 \mathrm{~kb}$ enclosed in a capsid composed of 60 copies of each of the three or four capsid proteins (VP1 to VP4). Human parechovirus 1 (HPEV1) is a member of the Parechovirus genus of the Picornaviridae family $(38,70)$. There are currently eight completely sequenced human parechovirus types and 14 described types (4, 19, 24, 30, $38,39,51,58,78)$. In addition, the Parechovirus genus currently has four Ljungan virus members that infect rodents. HPEV1 exhibits several distinct molecular characteristics compared to other picornaviruses $(38,71)$. These include the lack of the maturation cleavage of the capsid proteins VP0 to VP4 (Nterminal) and VP2 (C-terminal), existence of an approximately 30 -amino-acid-long extension to the $\mathrm{N}$ terminus of VP3, a unique nonstructural protein $2 \mathrm{~A}$, and a $5^{\prime}$ untranslated region that is more closely related to picornaviruses infecting animals than those infecting humans.

HPEV infections are common during the first years of life and are often mild or asymptomatic $(20,28,42,73,80)$. Recently, a number of new types have been identified, and their prevalence in stool samples, for example, highlights their clinical importance. Normally, they cause gastroenteritis and respiratory infections, but severe illnesses, such as infections of the central nervous system, generalized infections of neonates, and myocarditis, have also been associated with HPEV infections $(1,8,10,28,80)$. Currently, the role of the unique mo-

\footnotetext{
* Corresponding author. Mailing address: Institute of Biotechnology and Department of Biosciences, P.O. Box 65 (Viikinkaari 1), FIN00014 University of Helsinki, Finland. Phone: 3589191 59563. Fax: 3589191 59930. E-mail: sarah.butcher@helsinki.fi.

${ }^{\nabla}$ Published ahead of print on 16 June 2010.
}

lecular, structural, and antigenic characteristics of HPEVs in the pathogenesis of infection is unknown.

HPEV types 1, 2, 4, 5, and 6 are known to possess an RGD motif near the $\mathrm{C}$ terminus of VP1 that is known to facilitate binding of cellular ligands (e.g., fibronectin) to $\alpha_{\mathrm{v}}$ integrins. The motif is in an analogous position to motifs in coxsackievirus A9 (CAV9) and echovirus 9 (EV9; Barty strain) (Fig. 1). The role of the RGD sequence in cellular entry and subsequent replication of HPEV1 has been shown through blocking assays with RGD-containing peptides, mutation of the sequence, and function-blocking antibodies to $\alpha_{\mathrm{v}}$ integrins (11, $43,62,71)$. These results strongly suggested that $\alpha_{\mathrm{v}}$ integrins play a central role in the initiation of HPEV1 infection. Direct involvement of $\alpha_{\mathrm{v}}$ integrins in the infectious entry of HPEV1 was further confirmed by overexpression of human $\alpha_{\mathrm{v}} \beta_{1}$ and $\alpha_{v} \beta_{3}$ integrins in Chinese hamster ovary (CHO) cells, allowing successful virus infection (74). There are no reports yet on the identification of receptors for the HPEV types lacking the RGD motif (HPEV3, HPEV7, and HPEV8) (19, 39, 51).

Although the crystal structures of several picornaviruses have been determined $(3,26,34,35,44,57,59,65,68,72)$ and the receptor interactions have been studied in detail by X-ray crystallography, electron cryo-microscopy (cryo-EM), and threedimensional (3D) image reconstruction $(6,9,23,31,32,47$, $83)$, there is no structural information available for the parechoviruses or parechovirus-receptor complexes. Here, we compare the binding of $\alpha_{\mathrm{V}} \beta_{3}$ and $\alpha_{\mathrm{V}} \beta_{6}$ to HPEV1 in vitro by biochemical assays and determine the structures of HPEV1 and the corresponding HPEV1-integrin complexes.

\section{MATERIALS AND METHODS}

Production and purification of HPEV1 and integrin $\boldsymbol{\alpha}_{\mathbf{v}} \boldsymbol{\beta}_{\mathbf{6}}$. HPEV1 (Harris strain; ATCC) (38) was propagated in a human lung carcinoma cell line (A549; 
20

30

4 ㅇ

50

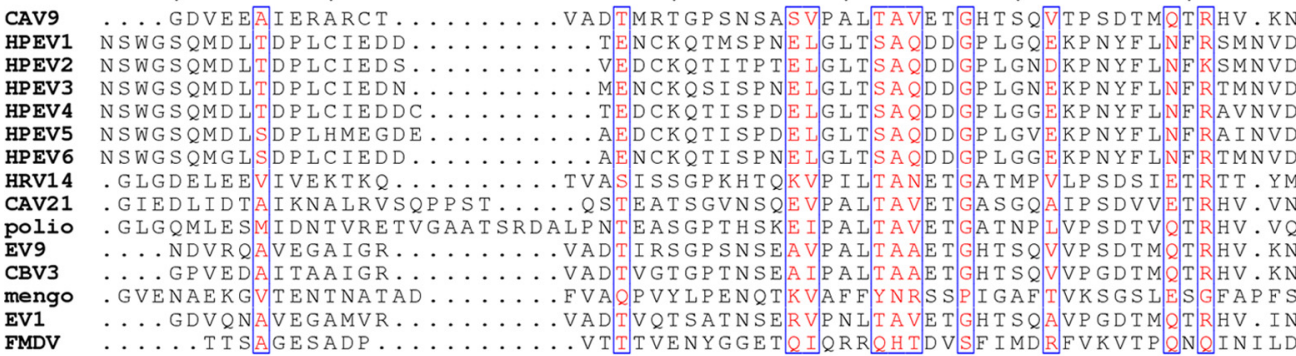

FMDV

CAV9

$\underset{80}{\mathrm{hZ}}$

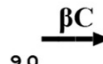

${ }_{100}^{\text {helelee }}$

BD

CAV9 YHSR SESTVENFLGRACVYMEEYKTT...... DKHVNKKFVAWPINTKQMVQMR.RKLEMFTYLRFDME

HPEV1 IFTVSHTKVDNLFGRAWFFMEHTFTNE............

HPEV2 IFTVSHTKVDNIFGRAWFAHVHDFTND.....................

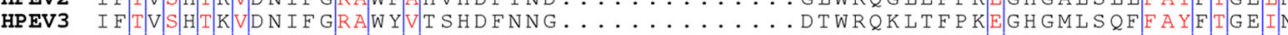

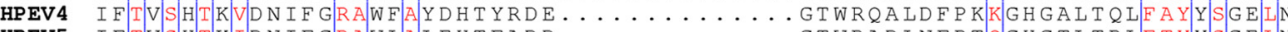

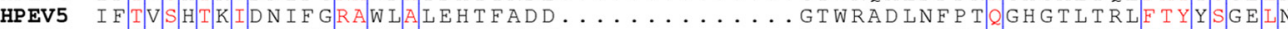

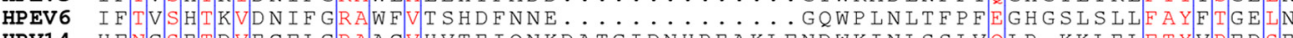

HRV14 HFNGSETDVECFLGRAACVHVTEIQNKDATGIDNHREAKLFNDWKINLSS LVQLR. KKLELFTYVREDSE

CAV21 YKTRSESCIESFFGRAACVIILSLTNSSK.... SGEEKKHFNIWNITYTDTVOIR. RKLEFFTYSRFDIE

polio HRSRSESSIESFFARGACVIIMTVDNPAS.... TTNKDKLFAVWKITYKDTVIR. RKIEFFTYSREDME

EV9 YHSRSSESTIENFLCRSACVRMAKYEARG ..... DPESTDRFDAWEISVRDMVQMR. RKCEMETYIRFDVE

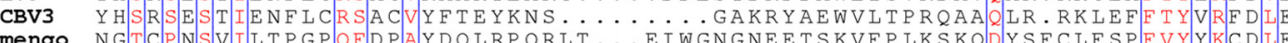

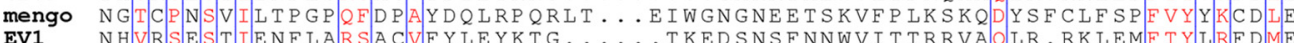

EV1 NHVRSESTIENFLARSACVFYLEYKTG...... TKEDSNSFNNWVITTRRVAQIR.RKLEMETYIRFDME

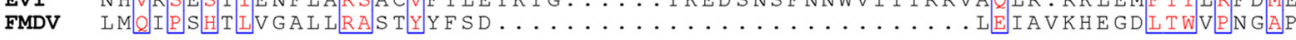

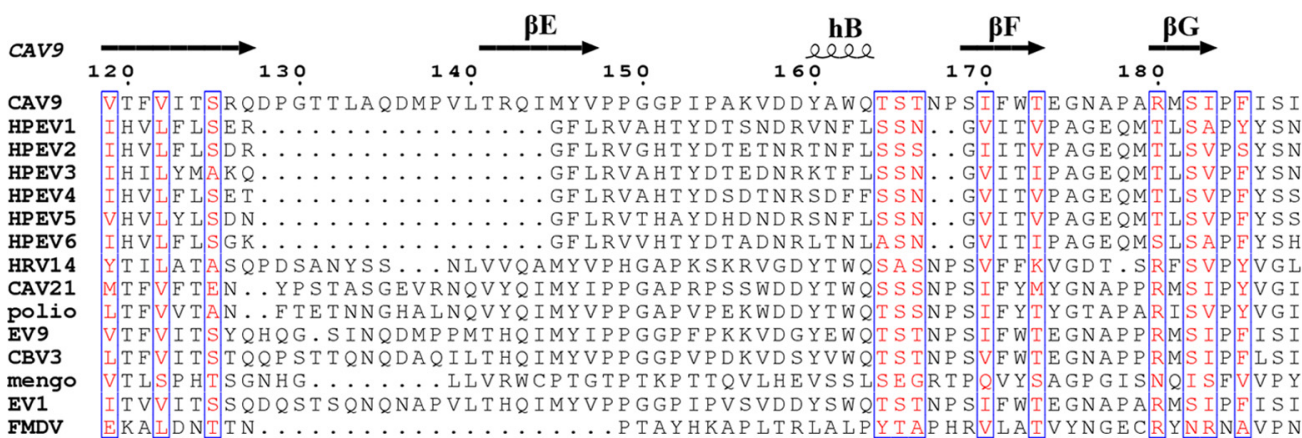

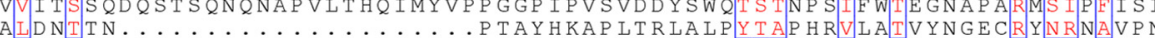

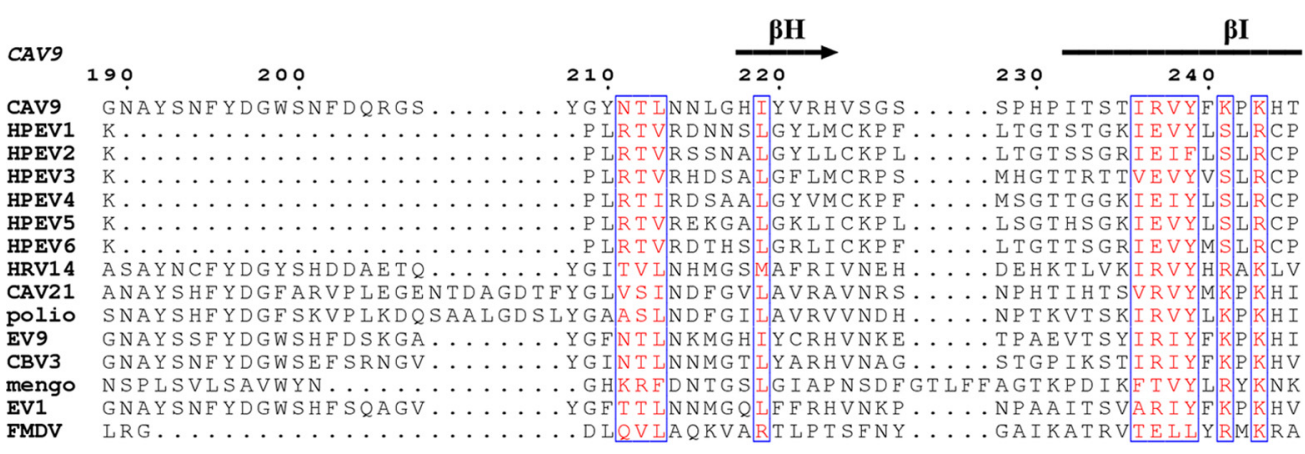

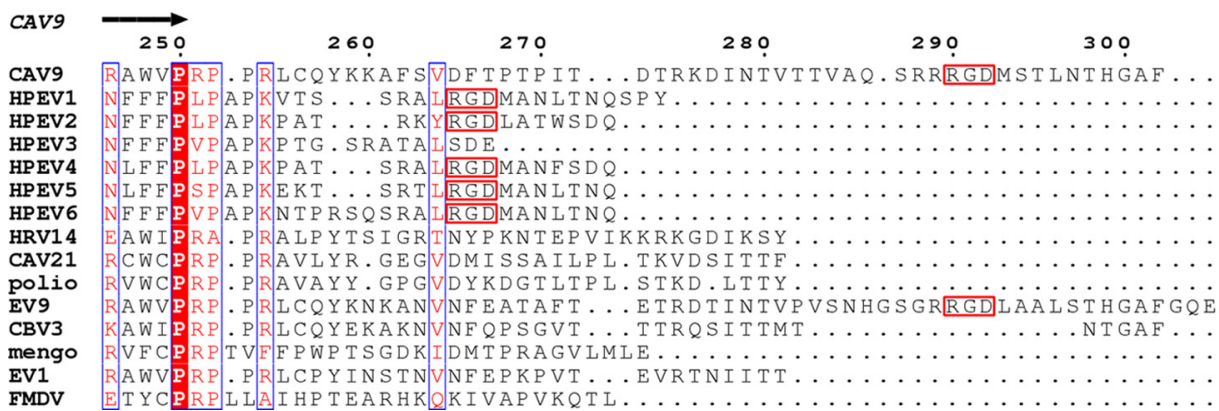

FIG. 1. Sequence alignments. Amino acid sequence alignment of the viral coat protein VP1 from different picornaviruses with the CAV9 secondary structure derived from the atomic model displayed above the alignment (34). The columns boxed in blue with red letters signify similarity, and the red column signifies identity. There is limited similarity between HPEV and other picornaviruses. C-terminal RGD motifs are boxed in red. 
ATCC) and purified in 5 to $20 \%$ sucrose gradients as described earlier (2). The soluble integrin $\alpha_{\mathrm{V}} \beta_{6}$ ectodomain was expressed in CHO cells cotransfected with plasmids encoding both $\alpha_{\mathrm{V}}$ - and $\beta_{6}$-subunits lacking the transmembrane domains (79) and purified by affinity chromatography on a GRGDSPK peptide affinity column $(79,81)$. Integrin $\alpha_{V} \beta_{3}$, isolated from human placenta and affinity purified on an $\alpha_{\mathrm{V}} \beta_{3}$-specific antibody column (BioMarket Ltd., Finland), was diluted in phosphate-buffered saline (PBS) below the critical micelle concentration to remove Triton X-100.

In vitro integrin binding assays. Binding of HPEV1 to $\alpha_{V} \beta_{3}$ and $\alpha_{V} \beta_{6}$ integrins was analyzed in a solid-phase integrin binding assay. Ninety-six-well plates (Costar High Binding) were incubated with $300 \mathrm{ng}$ of integrin $\alpha_{\mathrm{V}} \beta_{3}$ or $\alpha_{\mathrm{V}} \beta_{6}$ in coating buffer $\left(1 \mathrm{mM} \mathrm{MgCl}{ }_{2}\right.$ in PBS) overnight at $+4^{\circ} \mathrm{C}$. The wells were washed three times with coating buffer, blocked with binding buffer $(1 \%$ bovine serum albumin [BSA] in coating buffer) for $2 \mathrm{~h}$ at room temperature, and washed before addition of virus. After $30 \mathrm{~min}$ of incubation at room temperature, the unadsorbed inoculum virus was removed by thorough washing with PBS, followed by incubation with virus-specific antiserum for $1 \mathrm{~h}$. The washing step was repeated, and secondary anti-mouse/rabbit horseradish peroxidase (HRP) conjugate was added and incubated for a further hour at room temperature. Wells were stained with 3,3',5,5'-tetramethylbenzidine (TMB) peroxidase substrate, and the optical density was measured at $450 \mathrm{~nm}\left(\mathrm{OD}_{450}\right)$. A similar protocol was used to immobilize the virus in the wells to determine integrin binding, but instead of integrins, the plates were coated with virus, overlaid with integrins, and detected using nonfunctional blocking antibodies (MAB2074Z; Millipore) against integrin $\alpha_{V} \beta_{6}$ and rabbit antiserum against integrin $\alpha_{V} \beta_{3}$ (gift from Merja Roivainen, THL, Finland).

Plaque neutralization assay with soluble integrin $\alpha_{v} \beta_{3}$ or $\alpha_{v} \beta_{6}$. A total of 1,000 PFU of HPEV1 and two different amounts of integrin (20 or $200 \mathrm{ng}$ ) were mixed and incubated at room temperature for $1 \mathrm{~h}$. Confluent GMK cells were infected with virus-integrin suspensions at $+37^{\circ} \mathrm{C}$ for $15 \mathrm{~min}$ and overlaid with $0.5 \%$ carboxy methyl cellulose solution. The cells were incubated for 2 to 4 days at $+37^{\circ} \mathrm{C}$ before being stained with crystal violet, and plaques were counted. The experiment was repeated twice.

Peptide blocking assay. Ninety-six-well plates (Costar High Binding) were coated with $200 \mathrm{ng}$ of either integrin $\alpha_{\mathrm{V}} \beta_{3}$ or $\alpha_{\mathrm{V}} \beta_{6}$ in coating buffer $(1 \mathrm{mM}$ $\mathrm{MgCl}_{2}$ in PBS) overnight at $+4^{\circ} \mathrm{C}$. Wells were washed three times with coating buffer, blocked with binding buffer (1\% BSA in PBS with $1 \mathrm{mM} \mathrm{MgCl}_{2}$ ) for $1.5 \mathrm{~h}$ at room temperature (RT), washed, and preincubated with the peptides (RRR GDL, RRRGEL, or CRRRGDLC) for $45 \mathrm{~min}$ at RT. The peptide concentration used was at least 300 times greater than the integrin concentration. The peptide solution was then removed before purified virus was added. After a 30-min incubation at room temperature, the unadsorbed inoculum virus was removed by thorough washing, followed by incubation with virus-specific antiserum for $1 \mathrm{~h}$. The washing step was repeated, and secondary anti-mouse/rabbit horseradish peroxidase conjugate was added and incubated for another $1 \mathrm{~h}$ at room temperature. Wells were stained with 3,3',5,5'-tetramethyl benzidine peroxidase substrate, and absorbance was measured at the $\mathrm{OD}_{450}$.

Preparation of cryo-samples and electron microscopy. The vitrified samples were prepared from 3- $\mu$ l aliquots on freshly glow-discharged Quantifoil R2/2 (Quantifoil Micro Tools GmbH, Germany) and C-Flat 224 (Protochips Inc.) grids, as described previously (6). Samples of HPEV1 and either integrin $\alpha_{V} \beta_{3}$ or $\alpha_{V} \beta_{6}$ were mixed at a ratio of three integrin molecules per two binding sites and incubated together at room temperature for $\sim 1 \mathrm{~h}$ prior to plunging. The micrographs were recorded using a Gatan 626 cryo-holder maintained at $-180^{\circ} \mathrm{C}$ in an FEI Tecnai F20 microscope operated at $200 \mathrm{kV}$ and magnification of $\times 62,000$. The images were recorded on Kodak SO163 film under low-dose conditions. The film was developed in full-strength Kodak D19 developer for $12 \mathrm{~min}$

Image processing and 3D image reconstruction. Micrographs were inspected by eye and discarded if they contained crystalline ice or drift or were astigmatic. The remaining micrographs were scanned using a PhotoScan TD scanner (Z/I Imaging) with 7- $\mu \mathrm{m}$ sampling and 12-bit gray-scale readout. Digitized images were evaluated by determining the contrast transfer function of each micrograph using the program CTFFIND3 (56), and images containing drift or astigmatism were discarded. Particles were picked using the program ETHAN (45) and inspected by eye in the program suite EMAN (53). We next used the randommodel computation (RMC) procedure (85) to generate an initial reconstructed model of HPEV1 at $\sim 3 \mathrm{~nm}$ from 150 particle images. This map then served as the starting model to initiate full orientation and origin determinations of the entire set of images using AUTO3DEM (86). Corrections to compensate in part for the effects of the microscope contrast transfer function were performed as described elsewhere $(12,87)$. The final 3D map, reconstructed from 3,328 particles, was computed out to a resolution of $0.72 \mathrm{~nm}$, with a Gaussian function applied to attenuate the Fourier data smoothly to zero from 0.77 to $0.72 \mathrm{~nm}$. The resolution was estimated to be reliable to $0.85 \mathrm{~nm}$ by Fourier shell correlation analysis (threshold criterion, 0.5$)(75,76)$. We determined the hand of HPEV by the fit with the CAV9 atomic model. The final HPEV1 map served as a starting model for orientation and origin refinement of the HPEV1-integrin complex image data, and the reconstruction procedure described above was followed. Although the HPEV1- $\alpha_{\mathrm{V}} \beta_{6}$ map refined to $0.87-\mathrm{nm}$ resolution, it was ultimately rendered at a lower resolution $(1.0 \mathrm{~nm}$, with Gaussian smoothing applied from 1.05 to $1.0 \mathrm{~nm})$ to make it easier to see the integrin density. The HPEV1- $\alpha_{\mathrm{V}} \beta_{3}$ reconstruction had an estimated resolution of $1.5 \mathrm{~nm}$ and was computed out to $1.15 \mathrm{~nm}$, with Gaussian smoothing applied from 1.15 to $1.3 \mathrm{~nm}$. Visualization was done with CHIMERA (60).

Tomographic reconstructions of $\boldsymbol{\alpha}_{\mathbf{v}} \boldsymbol{\beta}_{6}$-labeled HPEV1. Nine tilt series of lowdose images for tomographic reconstructions were recorded automatically using a Gatan Ultrascan 4000 charge-coupled device (CCD) camera with the SerialEM software (54). Images were collected in $4^{\circ}$ increments over a range of $\pm 56^{\circ}$ for a $\times 68,000$ magnification series and in $3^{\circ}$ increments over a range of $\pm 60^{\circ}$ for a $\times 39,400$ magnification series. The two different magnifications resulted in samplings of 0.22 and $0.38 \mathrm{~nm} /$ pixel, respectively. Colloidal gold particles $(10 \mathrm{~nm})$ included in the sample served as fiducial markers for image alignment. The data from the $\times 68,000$ and $\times 39,400$ magnification series were binned by a factor of 4 $(0.88 \mathrm{~nm} /$ pixel $)$ and $2(0.76 \mathrm{~nm} /$ pixel $)$, respectively, prior to the calculation of tomographic reconstructions and application of a nonlinear anisotropic diffusion filter in IMOD $(48,55)$.

Sequence analysis and homology modeling. The amino acid sequence of HPEV1 VP1 (GenBank accession number S45208) (38) was compared with the VP1 sequences of HPEV2 (NC 001897) (41), HPEV3 (AB084913) (39), HPEV4 (DQ315670) (8), HPEV5 (AM 235749$)$ (4), HPEV6 (AB252582) (78), CAV9 (D00627) (17), human rhinovirus 14 ([HRV14] K02121) (69), coxsackievirus A21 ([CAV21] AF546702) (15), poliovirus 1 (NC_002058) (63), EV9 (X92886) (90), coxsackievirus B3 ([CBV3] M33854) (46), encephalomyocarditis virus (EMCV) mengovirus (AJ617356) (18), echovirus 1 ([EV1] AF029859) (21), and foot-andmouth disease virus ([FMDV] CAA24362) (49) using ClustalW (50). The secondary structure of CAV9 (34) was then added to the alignment using Espript (25) (Fig. 1). The $\beta_{6}$-subunit of integrin $\alpha_{V} \beta_{6}$ (GenBank accession number NP_000879) was modeled using Phyre (7).

Protein structure accession numbers. The reconstructions have been deposited in the Electron Microscopy Data Bank at the European Bioinformatics Institute under accession codes EMD-1688, EMD-1689, and EMD-1690.

\section{RESULTS}

Comparison of HPEV1 to other picornaviruses. Sequence comparisons revealed that parechoviruses have very limited sequence identity (around 14\%) to other picornaviruses (Fig. $1)$. The secondary structure elements including the eightstranded $\beta$-barrels in the HPEV major capsid proteins VP0 and VP3 are conserved. However, homology modeling based on the known atomic models was unsuccessful with Phyre and I-Tasser modeling software (7, 82, 88, 89). Instead, we confirmed the homology by cryo-EM and image reconstruction of HPEV1 to 0.85-nm resolution (Fig. 2 and 3; Table 1). Vitrified HPEV1 samples consisted mostly of intact viral particles (Fig. 2A) and very few empty capsids (approximately 1\%) (Table 1). The external appearance of the 28-nm-diameter particle is consistent with that of other picornaviruses (Fig. 3). Notably, the HPEV1 particle is much smoother than that of many of the other picornaviruses, for instance, CAV9, resembling mostly FMDV (Fig. 3). The smoothness can be explained by the much shorter surface loops in VP1, evident from the sequence alignments. According to the alignments, the loop between $\beta$-strands $\beta D$ and $\beta E$ in VP1 is either very short or possibly missing completely, potentially merging the strands into one and leaving seven strands to form the $\beta$-barrel as in FMDV VP1 (Fig. 1 and 4B) (59). In contrast, the $\sim 13$-residue CAV9 $\beta$ D- $\beta$ E loops from five VP1 subunits come together to form the center of each 5-fold protrusion on the capsid surface. Additionally, there are major deletions in the HPEV $\beta B-\beta C$ 


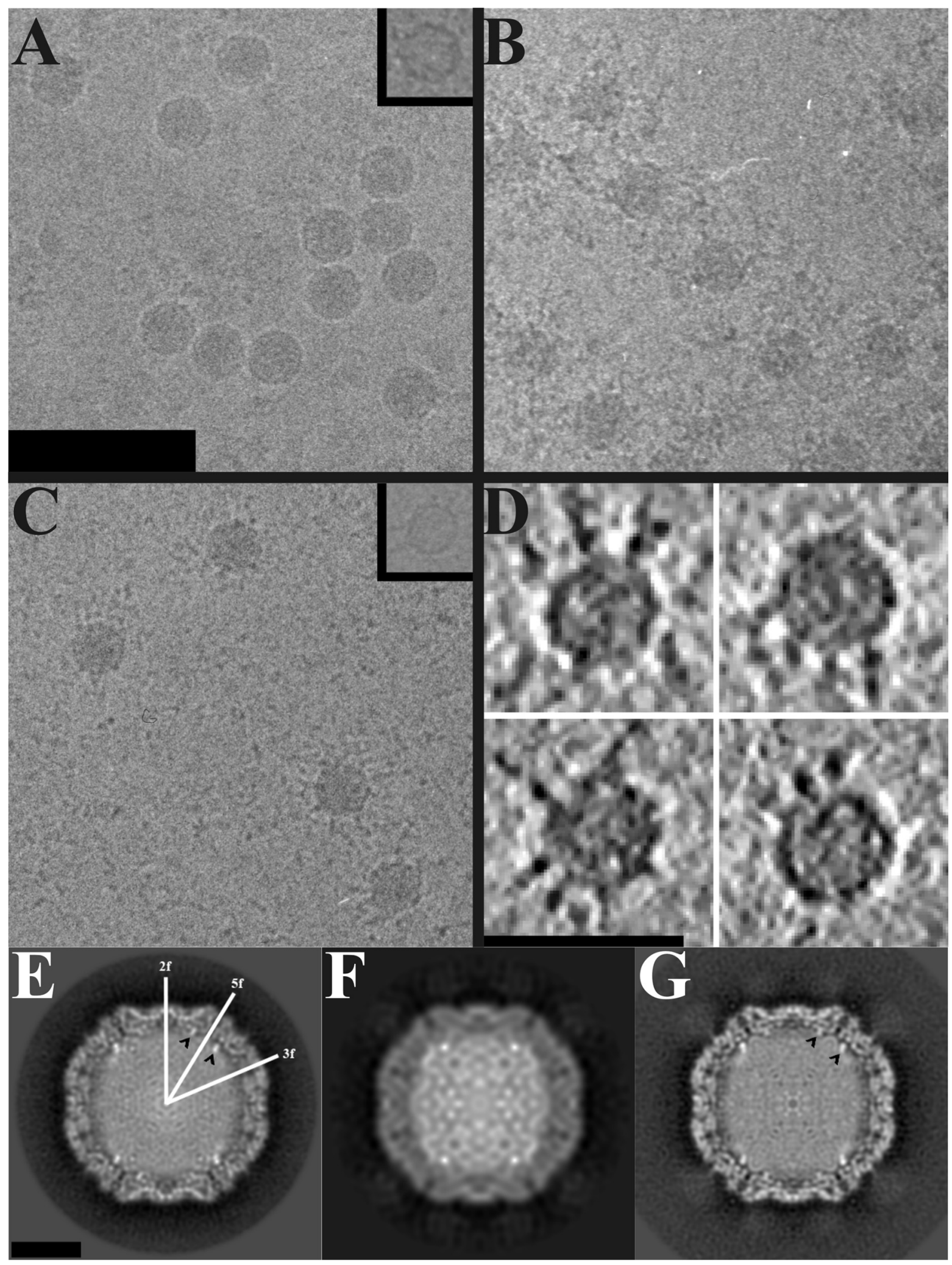

FIG. 2. Electron cryo-microscopy of HPEV1 and HPEV1 complexed with integrins. (A) Micrograph of HPEV1 at $2.8-\mu \mathrm{m}$ underfocus. (B) Micrograph of HPEV1 complexed with integrin $\alpha_{\mathrm{V}} \beta_{3}$ at $2.5-\mu \mathrm{m}$ underfocus. (C) Micrograph of HPEV1 complexed with integrin $\alpha_{\mathrm{V}} \beta_{6}$ at 3.1- $\mu \mathrm{m}$ underfocus. Scale bar, $100 \mathrm{~nm}$ (A; also for B and C). An empty particle image is inset in panels A and C. (D) Slices (0.76 nm thick) through tomographic reconstructions of four representative $\alpha_{\mathrm{V}} \beta_{6}$-labeled HPEV1 particles. Scale bar, $50 \mathrm{~nm}$. The integrin can be seen bound to the particles in panels B and C, but they are clearest in the tomographic data. (E) Central section of the HPEV1 reconstruction. Twofold, 3-fold, and 5 -fold axes of symmetry are indicated. (F) Central section of the HPEV1 complexed with integrin $\alpha_{\mathrm{V}} \beta_{3}$ reconstruction. (G) Central section of the HPEV1 complexed with integrin $\alpha_{V} \beta_{6}$ reconstruction. Scale bar, $10 \mathrm{~nm}$ (E; also for F and $\mathrm{G}$ ). The black arrowheads in panels $\mathrm{E}$ and $\mathrm{G}$ indicate strong fingers of density near a 5 -fold axis of symmetry. 


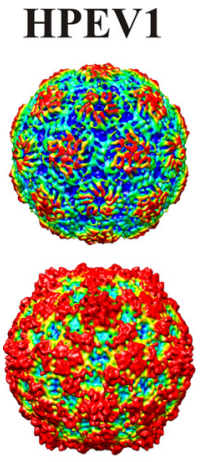

CAV9

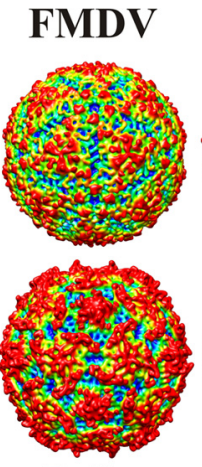

Polio
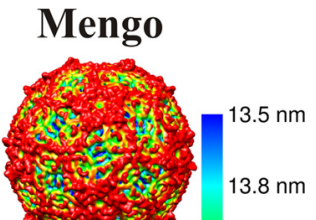

$14.1 \mathrm{~nm}$

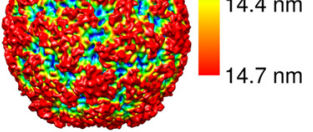

HRV14

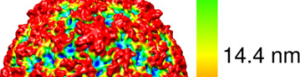

FIG. 3. Comparison of the icosahedrally symmetric 0.85 -nm-resolution HPEV1 reconstruction with the atomic models of other picornaviruses. HPEV1, FMDV (Protein Data Bank [PDB] code 1bbt), mengovirus (PDB 2mev), CAV9 (PDB $1 \mathrm{~d} 4 \mathrm{~m}$ ), poliovirus (1hxs), and HRV14 (4rhv). The X-ray models have been filtered to 0.85 -nm resolution, and all models are rendered as isosurface representations at 2 standard deviations above the mean, viewed down a 2-fold axis of symmetry. This comparison demonstrates the diversity of picornavirus surface features as well as the unique features of HPEV1. The models have been colored using radial-depth cueing in CHIMERA (bar, 13.5to $14.7-\mathrm{nm}$ radius) $(60)$.

loop and the $\beta \mathrm{G}-\beta \mathrm{H}$ loop compared to CAV9, where these longer loops form protrusions between the 5-fold and 3-fold axes. Although the HPEV1 and CAV9 capsids are similar in thickness and diameter, when the CAV9 atomic model is fitted into the HPEV1 map, the three loops extend beyond the density envelope (Fig. 4). These results further support the view that the abbreviated loops are responsible for FMDV and HPEV1 having such a smooth appearance relative to the other picornaviruses (Fig. 1, 3, and 4). Thus, it is highly likely that HPEV1 has the $\mathrm{T}=1$ (pseudo $\mathrm{T}=3$ ) symmetry that is common to other picornaviruses.

Protein-RNA interactions. The genome of HPEV1 appears to be organized close to the protein shell (Fig. 2E to G). There are also five prominent, $\sim 3$-nm-long, fingerlike regions of high density extending radially from the inner surface of the capsid and into the genome beneath each vertex (Fig. 2E, arrowheads, and 4A, C, D, and E). Fitting of the CAV9 atomic model (34) into the HPEV1 EM reconstruction allowed us to interpret which proteins most likely interact with the genome. The fitting placed the N termini of VP1 and VP4 of the CAV9 atomic model directly into these protrusions at the protein-RNA interface. The EM density extends much further into the interior (Fig. 4E) than the atomic model. Thus, we predict that the $\mathrm{N}$ termini of the HPEV1 VP0 (equivalent to the VP4 N terminus) and VP1 interact with RNA around the 5-fold axes. Since the density is much higher than that of either the rest of the protein capsid or the majority of the RNA, these fingers may contain highly ordered duplex RNA as well as protein.

Integrin binding assays. To analyze the binding of integrin $\alpha_{V} \beta_{3}$ and $\alpha_{V} \beta_{6}$ to HPEV1, the integrins were immobilized, one species at a time, on a microtiter plate, and the virus was overlaid on top (Fig. 5). HPEV1 was found to bind to both integrins with similarly high efficiencies. This was expected as there are 60 RGD motifs on the virus surface that are potentially accessible to the integrins, and it is assumed that integrins immobilized at high density will have several attachment sites on the virus surface, thus increasing avidity of binding. In contrast, when immobilized HPEV1 was overlaid by integrins (one binding site per integrin), a clear difference in the affinity between the integrin species and HPEV1 was observed. Integrin $\alpha_{V} \beta_{6}$ bound efficiently to HPEV1 while integrin $\alpha_{V} \beta_{3}$ exhibited only background-level affinity to HPEV1 (Fig. 5B). Similar results have recently been observed for the RGDcontaining enterovirus, CAV9 (33).

Effect of soluble integrin $\alpha_{v} \beta_{3}$ and $\alpha_{v} \beta_{6}$ on HPEV1 infectivity. Recently, it has been shown that $\alpha_{V} \beta_{6}$, but not $\alpha_{V} \beta_{3}$, blocks CAV9 infectivity $(33,81)$. To determine whether this is also a property of integrin binding to HPEV1, excess amounts of integrin were incubated with HPEV1, and the infectivity was determined by plaque assay (Fig. 5C). Soluble $\alpha_{\mathrm{V}} \beta_{6}$ blocked HPEV1 infectivity while soluble $\alpha_{V} \beta_{3}$ might slightly enhance infectivity, but this was not a statistically significant effect. These results suggest that integrin $\alpha_{\mathrm{V}} \beta_{6}$ binds to HPEV1 with high affinity in vitro, blocking the access to cell surface receptors.

RGD peptide-blocking assay. Previously, it has been shown that RGD peptides block HPEV1 infectivity in A549 cells (71). To study whether RGD peptides block direct virus-integrin interaction in vitro, the peptides were incubated with immobilized integrins, followed by incubation with the virus. The addition of different RGD peptides decreased virus binding to the integrins compared to the addition of a negative-control peptide, thereby confirming that the RGD motif is one of the major HPEV1 binding sites for both integrins $\alpha_{V} \beta_{3}$ and $\alpha_{V} \beta_{6}$ (Fig. 5D and $\mathrm{E}$ ). Thus, the apparent differences in the in vitro integrin binding of HPEV1 (Fig. 5A and B) and the ability of $\alpha_{V} \beta_{6}$, but not $\alpha_{V} \beta_{3}$, to block infection should be explained by factors other than RGD binding alone.

Homology modeling of integrin $\boldsymbol{\alpha}_{\mathbf{v}} \boldsymbol{\beta}_{\mathbf{6}}$. The differences observed in the affinities of the integrins $\alpha_{V} \beta_{3}$ and $\alpha_{V} \beta_{6}$ for HPEV1 (Fig. 5) prompted us to investigate how these integrins interact with the capsid. There is an atomic model of the extracellular domain of the $\alpha_{\mathrm{V}} \beta_{3}$ integrin in complex with an RGD ligand (84) but not of the $\beta_{6^{-}}$-subunit. The RGD binding site has contributions from both the $\alpha_{V^{-}}$and $\beta_{3}$-subunits. Pairwise comparison of the integrin subunit $\beta_{3}$ and $\beta_{6}$ amino acid sequences (66) revealed that they are $47.6 \%$ identical. To address whether or not the differences detected in the binding and infectivity studies were due to structural differences in the $\beta$-subunits of the integrins, a high-reliability (estimated precision, $100 \%$; E-value, 0 ) homology model of the $\beta_{6}$-subunit was

TABLE 1. Statistics of HPEV1 and HPEV1 integrin complex reconstructions

\begin{tabular}{lccc}
\hline \multirow{1}{*}{ Parameter } & \multicolumn{3}{c}{ Value for the parameter } \\
\cline { 2 - 4 } & HPEV1 & HPEV1- $\alpha_{\mathrm{V}} \beta_{6}$ & HPEV1- $\alpha_{\mathrm{V}} \beta_{3}$ \\
\hline No. of micrographs & 68 & 93 & 16 \\
No. of full particles & 3,328 & 2,105 & 431 \\
No. of empty particles & 25 & 71 & 3 \\
$\%$ of empty particles & 0.8 & 3.4 & 0.7 \\
Defocus minimum (nm) & 946 & 793 & 1,486 \\
Defocus maximum (nm) & 3,032 & 3,106 & 2,922 \\
Resolution (nm) & 0.85 & 0.87 & 1.5 \\
\hline
\end{tabular}



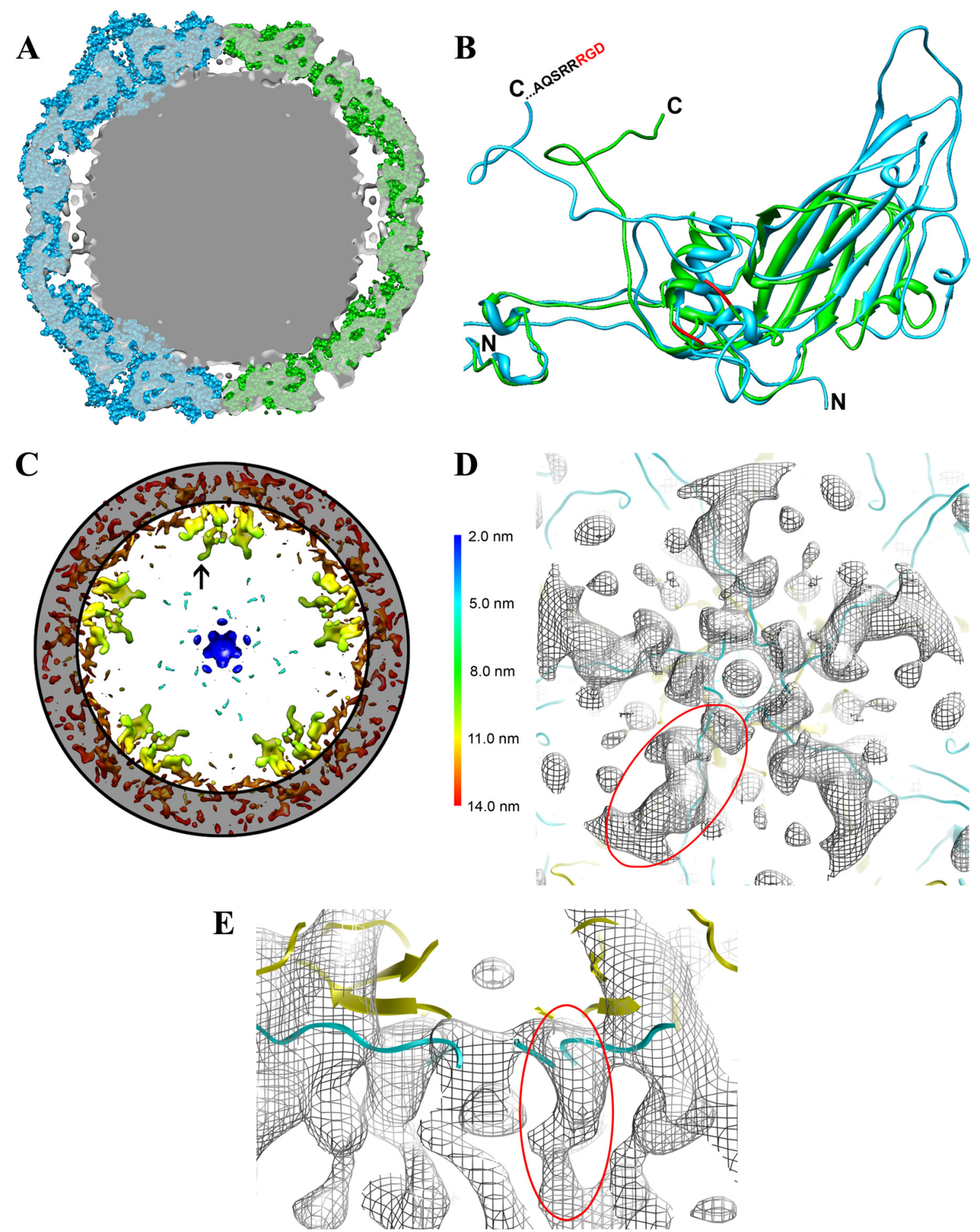

FIG. 4. Capsid protein RNA contact. (A) Central section of the 0.85-nm-resolution HPEV1 reconstruction (gray; transparent) with a CAV9 X-ray structure (cyan) fitted on the left-hand side and an FMDV X-ray structure (green) fitted in on the right-hand side of the cryo-EM reconstruction. X-ray structures are presented as sphere models. The CAV9 model protrudes from the HPEV1 density at the 5-folds due to the long surface loops in the $\beta$-barrel of CAV9 VP1, whereas FMDV offers a better fit at the 5-fold due to shorter loops. (B) Comparison of CAV9 VP1 (blue) and FMDV VP1 (green) presented as a ribbon. The C and N termini of both CAV9 VP1 and FMDV VP1 are indicated. The loop containing the RGD motif in FMDV is not resolved in the X-ray model, but the nearest three amino acids resolved on both sides of the loop are indicated (red). The extended loops of CAV9 compared to FMDV are also evident in this panel. (C) Slabbed section of the 0.85-nm-resolution HPEV1 reconstruction rendered at 3 standard deviations above the mean, viewed along a 5-fold axis of symmetry and depth queued to reveal the five high-density finger-like protrusions (black arrow) inside the capsid under each vertex. The position of the capsid layer is indicated with a gray ring. (D) A section showing a single set of fingers viewed from the inside the capsid. HPEV1 density is shown as a gray mesh with the superimposed atomic models of CAV9 VP1 (cyan) and VP4 (vellow) in ribbon. This view illustrates how the N termini of CAV9 VP1 and VP4 fit the finger-like densities. (E) The view from panel D tilted $90^{\circ}$ and cropped for clarity. This view shows how the finger-like density seen in the HPEV1 reconstruction extends even farther into the RNA than in the atomic models of CAV9 VP1 and VP4. One of the finger-like densities is indicated (circled in red) in panels D and E. 

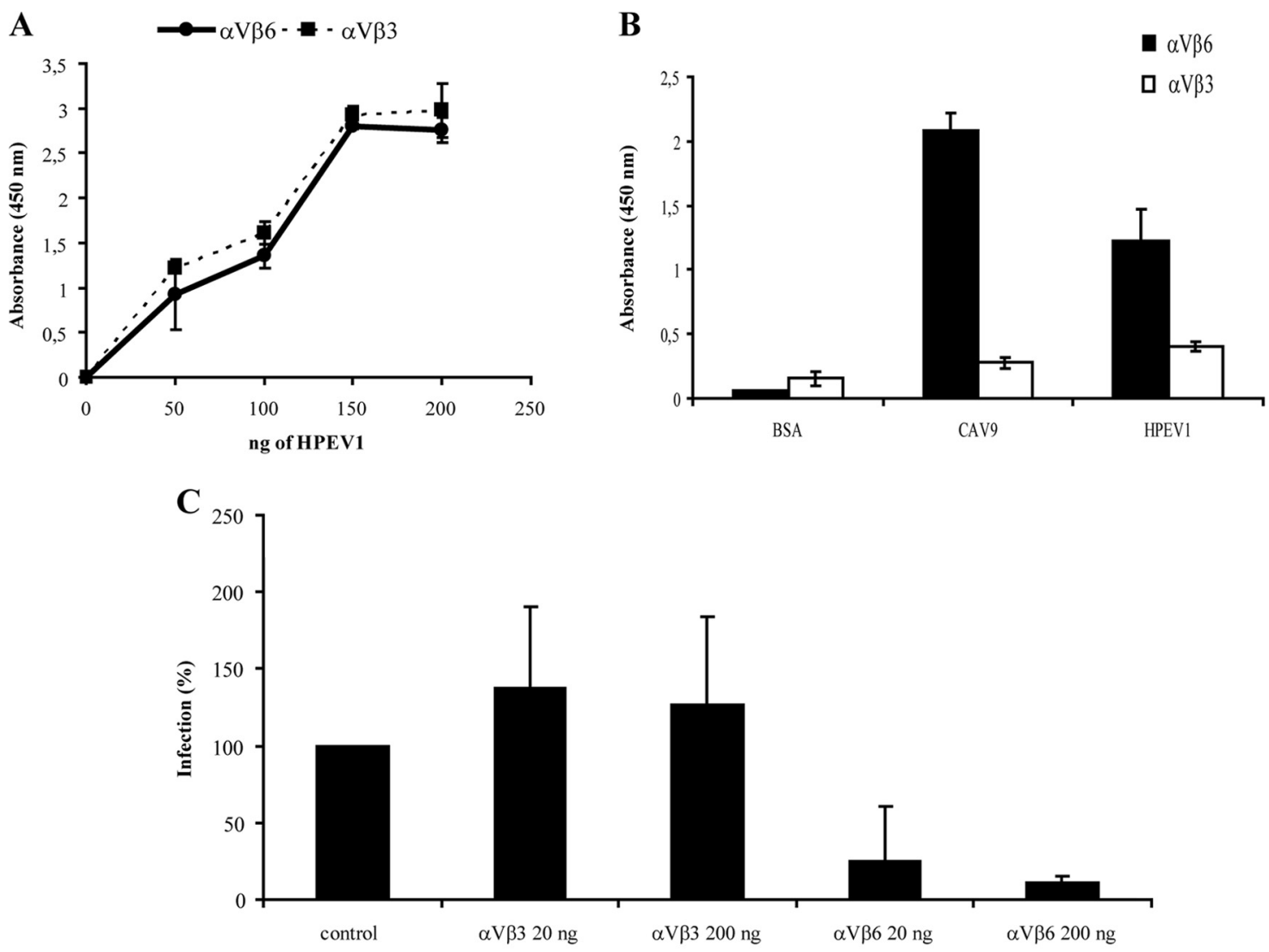

D $\alpha V \beta 6$-integrin binding

口RRRGE

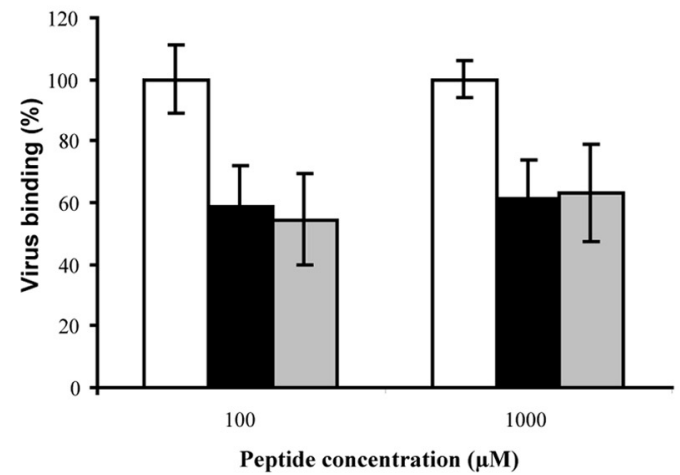

E

$\alpha V \beta 3$-integrin binding

口RRRGEL

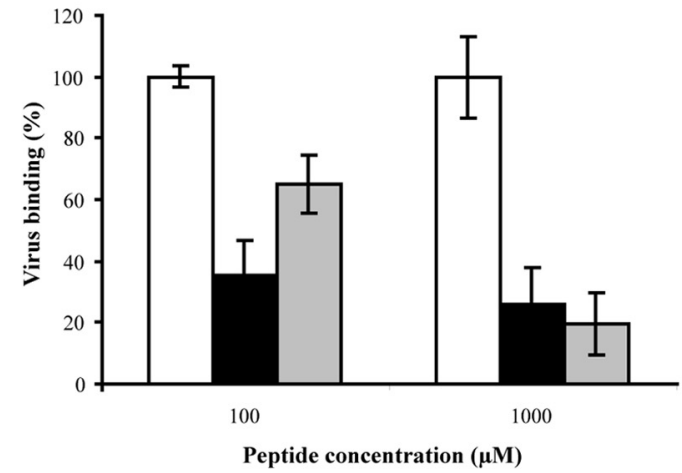

FIG. 5. Integrin binding assays. (A) HPEV1 in vitro binding assay to immobilized integrins (avidity assay). Integrin $\alpha_{\mathrm{V}} \beta_{3}$ and $\alpha_{\mathrm{V}} \beta_{6}(300 \mathrm{ng}$ ) were passively immobilized onto microtiter wells, and 0,50,100, 150 or $200 \mathrm{ng}$ of HPEV1 was overlaid and incubated for $2 \mathrm{~h}$ before detection by virus-specific antibody followed by HRP-conjugated secondary antibody. Wells were incubated with TMB $\left(\mathrm{H}_{2} \mathrm{O}_{2}\right.$ substrate), the reaction was stopped by adding $100 \mu \mathrm{l}$ of $0.45 \mathrm{M} \mathrm{H}_{2} \mathrm{SO}_{4}$, and the absorbance was read at the $\mathrm{OD}_{450}$. Range of two parallel experiments is shown. The experiment was repeated three times with identical results. (B) Binding of integrins to immobilized HPEV1 (affinity assay). A fixed amount (200 ng) of HPEV1 was immobilized onto wells, and binding of $300 \mathrm{ng}$ of integrin $\alpha_{\mathrm{V}} \beta_{3}$ and $\alpha_{\mathrm{V}} \beta_{6}$ was determined by specific antibodies. Similar amounts of CAV9 (33) and BSA were used as positive and negative controls, respectively. Average values of two independent experiments are shown. (C) Plaque reduction assay with soluble integrins. A total of 1,000 PFU of HPEV1 was incubated with $20 \mathrm{ng}$ or $200 \mathrm{ng}$ of integrins $\alpha_{\mathrm{V}} \beta_{3}$ and $\alpha_{\mathrm{V}} \beta_{6}$ for 1 h prior to cell infection. Plaques were counted 2 to 4 days postinfection. The infectivity was compared to that of the control (virus incubated without integrins). Data are the average of two independent experiments. (D and E) In vitro peptide blocking assay. Wells were coated with 200 ng of integrins $\alpha_{\mathrm{V}} \beta_{3}$ and $\alpha_{\mathrm{V}} \beta_{6}$ and preincubated with 100 and 1,000 $\mu \mathrm{M}$ concentrations of peptide RRRGDL, CRRRGDLC, or RRRGEL (as a negative control; $100 \%$ virus binding) before virus was added. Virus binding was detected by virus-specific antiserum followed by secondary anti-mouse/ rabbit HRP conjugate. Virus binding was calculated by adjusting absorbance values of the control to $100 \%$. The standard deviations of two independent experiments with five measuring points are shown. 

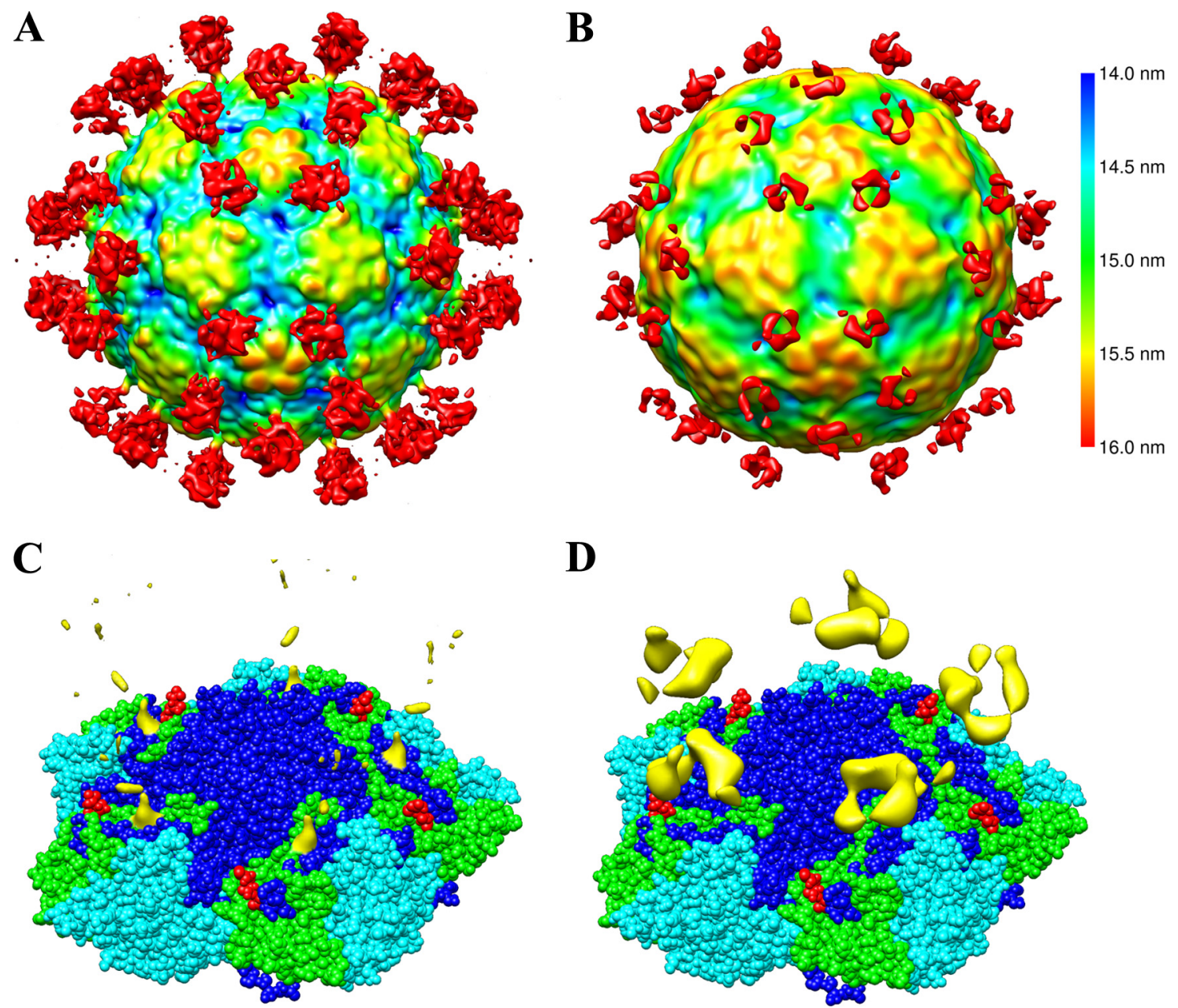

FIG. 6. HPEV1-integrin interactions. (A) An isosurface representation of the 1-nm-resolution reconstruction of HPEV1 complexed with integrin $\alpha_{\mathrm{V}} \beta_{6}$ at 0.15 standard deviations above the mean density viewed down a 2-fold axis of symmetry and depth queued. (B) An isosurface representation of the 1.5-nm-resolution reconstruction of HPEV1 complexed with integrin $\alpha_{\mathrm{V}} \beta_{3}$ at the mean density viewed down a 2-fold axis of symmetry and depth queued. The color key applies to panels A and B. (C) An isosurface representation of just the integrin $\alpha_{V} \beta_{6}$ density at 0.44 standard deviations above the mean in yellow, displayed on top of the CAV9 X-ray model. Residues PTP of CAV9 VP1 are covered by the integrin density. (D) An isosurface representation of just the integrin $\alpha_{V} \beta_{3}$ density (yellow) displayed on top of the CAV9 X-ray model. The reconstruction of HPEV1 complexed with integrin $\alpha_{V} \beta_{3}$ is rendered at the mean to reveal the weak integrin density. The atomic models in panels $C$ and D are shown as a sphere presentation of five copies of VP1, VP2, and VP3. VP1 is shown in dark blue, VP2 is in cyan, and VP3 is in green. The four C-terminal amino acids (VTTV) of the CAV9 VP1 atomic model are shown in red to illustrate the likely position of the RGD loop in CAV9.

generated using Phyre (7). The comparison of the $\beta_{6}$ homology model to the $\mathrm{X}$-ray structure of $\beta_{3}$ revealed the subunits to be topologically very similar, probably conserving the $\alpha_{\mathrm{V}}$ contribution to the binding site (Chimera [60] backbone root mean square deviation [RMSD], $0.05 \mathrm{~nm})$. The main RGD-interacting loop from $\beta_{3}$ (VSRNRDAPEG) is only partially conserved in $\beta_{6}$ (ISANIDTPEG). Thus, the electrostatic interactions of the integrin $\beta$-subunits with the virus are predicted to differ.

Structure of the virus-receptor complex. Biochemical studies indicate that both $\alpha_{V} \beta_{3}$ and $\alpha_{V} \beta_{6}$ bind to HPEV1 in vitro although $\alpha_{V} \beta_{6}$ binds to the capsid with the highest affinity (Fig. 5). This led us to vitrify samples of HPEV1 complexed with both integrin species in the hope of producing cryo-EM reconstructions that would reveal the integrin binding site. Inspection of these samples confirmed that many of the viral particles had bound integrin (Fig. 2B and C). Integrin binding was further verified by cryo-electron tomographs which showed a few integrins bound per particle, apparently in many different conformations (Fig. 2D). The ratio of empty capsids to full capsids remained unchanged when the virus was incubated at room temperature with the $\alpha_{V} \beta_{3}$ integrin for times ranging from $30 \mathrm{~min}$ to $2 \mathrm{~h}$ (Table 1 ). The percentage of empty particles increased $\sim 4$-fold during incubation with integrin $\alpha_{\mathrm{V}} \beta_{6}$, from 0.8 to $3.4 \%$; however, this was not statistically significant ( $Z$-test $P$ value of 0.32 ).

The structure of HPEV1, complexed with either of the integrins, features extra density in similar positions on the outside of the particle (Fig. 6). It should be noted that although the integrin heterodimer has a molecular mass of about 200 $\mathrm{kDa}$ and was visibly labeling all particles picked from the micrographs, the integrin density in the reconstruction is visible at only a low threshold, and even then the density is partial. Cryo-tomograms of the HPEV1-integrin complexes show variations in conformation, location, and number of integrins 
bound per particle that could explain this loss in signal (Fig. 2D). The footprint of the integrin molecule on the capsid surface was identifiable in the HPEV1- $\alpha_{V} \beta_{6}$ complex and resides between the 5-fold and the 3 -fold symmetry axes. While the binding site of the $\alpha_{\mathrm{V}} \beta_{3}$ integrin could not be discerned in the reconstruction, the overall position of the density at higher radii overlapped with that of the $\alpha_{V} \beta_{6}$, so we infer that the binding is similar for both molecules.

We made the reasonable assumption that the coat protein organization of HPEV1 is similar to that of CAV9 in order to identify the integrin footprint on the virus. Comparison with the CAV9 X-ray structure places the footprint (Fig. 6C, yellow density) directly on CAV9 VP1 on top of amino acids 268 to 270 (PTP). This is adjacent to the predicted position of the HPEV1 RGD loop based on sequence alignments (Fig. 1). Hence, we conclude that in line with the biochemical data, the integrin binds to the RGD loop of HPEV1 VP1.

\section{DISCUSSION}

In our studies we have analyzed the interaction of two integrins $\left(\alpha_{V} \beta_{3}\right.$ and $\left.\alpha_{V} \beta_{6}\right)$ with HPEV1 and determined the footprint of $\alpha_{\mathrm{V}} \beta_{6}$ on the capsid of HPEV1 using cryo-electron microscopy, three-dimensional image reconstruction, difference imaging, and comparison to the structure of CAV9. We show that the quaternary HPEV1 structure does, indeed, have similarity to some entero-, rhino-, and cardioviruses, despite very limited amino acid sequence identity (Fig. 1 and 3). The highest amino acid sequence identity to HPEV1 outside the parechovirus family is with EMCV mengovirus (for VP1, $19.9 \%$; for VP3, 18.6\%). We note that the rather truncated appearance of the 5-fold vertex of HPEV1 and the grand canyon stretching from 5-fold vertex to 5-fold vertex are probably a consequence of truncated surface loops in VP1. In fact, the $\beta \mathrm{D}-\beta \mathrm{E}$ loop may be completely deleted, leading to a sevenstranded $\beta$-barrel, as in FMDV, rather than an eight-stranded $\beta$-barrel, as has been found in all other picornavirus structures determined to date.

The uncoating mechanism of HPEV1 is still largely unknown. Uncoating events have been most thoroughly studied in poliovirus where, upon receptor binding, VP4 is released (5), and the N terminus of VP1 is externalized and binds to liposomes (22). It has been hypothesized that the VP1 $\mathrm{N}$ termini, perhaps in conjunction with VP4, bind to the cellular membrane to open a pore through which the RNA is then released into the cytosol $(16,22)$. Uncoating has also been studied for some minor-receptor group rhinoviruses, e.g., HRV2, where the conversion to the A particle is triggered by the acidic $\mathrm{pH}$ of the endosome, after which the RNA is hypothesized to exit via a pore formed by exposed hydrophobic sequences of VP1 and possibly VP4 $(13,61)$. In contrast, for the major-receptor group rhinoviruses such as HRV14, uncoating is triggered in endosomes by binding to intercellular adhesion molecule 1 (ICAM-1), leading to release of VP4, disruption of the endosomal membrane, and release of RNA $(27,67)$.

In HPEV1, VP0 is not cleaved to VP2 and VP4, leading us to speculate that if VP0 is indeed released or externalized, there may be additional steps required to allow RNA release, as VP0 is a much larger protein than VP4. The RNA-protein interactions that we predicted were mapped to the $\mathrm{N}$ termini of VP0 and VP1 in both HPEV1 and HPEV1 complexed with integrins (Fig. 2E, F, and G). Hence, externalization of these $\mathrm{N}$ termini could occur during uncoating. Interactions with these two $\mathrm{N}$ termini and RNA could also be important in particle assembly. We did not see any large conformational changes in the capsid after integrin binding. We wanted to know if binding under these conditions induced release of the RNA, so we measured the ratio of empty to full particles in the control and integrin-bound virus samples. We found no statistically significant indication that the virus-integrin complexes had lost RNA to form empty capsids or had dissociated as a consequence of the interaction. Thus, it seems unlikely that either of the integrins provoke uncoating in vitro.

We have carried out both biochemical and cryo-EM analyses to confirm the binding of both integrin $\alpha_{V} \beta_{3}$ and $\alpha_{V} \beta_{6}$ to HPEV1. We conclude that both integrins bind, at least partially, to the RGD loop located in the C terminus of VP1. Additionally, the biochemical data suggest that HPEV1 possesses higher motif-to-motif affinity to integrin $\alpha_{V} \beta_{6}$ than to $\alpha_{V} \beta_{3}$. The $\alpha_{V} \beta_{6}$ integrin footprint on the capsid was clearly resolved to lie between the 5-fold and 3-fold axes of symmetry. The $\alpha_{\mathrm{V}} \beta_{3}$ integrin density above the capsid was located in a similar position although a direct contact to the capsid was not seen. Homology modeling revealed amino acid sequence variability in the integrin loop interacting with the RGD motif. Considering these findings, it is likely that the observed differences in binding affinity are due to differences in the electrostatic interactions caused primarily by the variability of the $\beta$-subunit molecules rather than different interaction sites with the viral capsid.

It has been shown that deletion of the RGD motif is lethal in HPEV1 (11) but not in CAV9 (64). However, some HPEV types, e.g., HPEV3, lack the RGD motif. In the future, it would be very interesting to determine what enables CAV9, but not HPEV1, to survive the deletion of the RGD motif and furthermore to determine if there are additional molecules involved in HPEV1 and HPEV3 cell entry.

Although we have pinpointed an integrin binding site on the capsid surface, there are still issues limiting the analysis of the interactions. Our icosahedrally symmetric reconstructions of the complexes display only partial integrin density (Fig. $2 \mathrm{~F}$ and G). Two reasons for the smearing out of the density can be seen from the tomographic data (Fig. 2D): only a few (one to six), rather than the maximum complement of 60 , integrin molecules apparently bound to a single HPEV1 particle, and the integrins showed conformational flexibility. The HPEV1 RGD loop may also be flexible, as noted for the CAV9 virion and for adenovirus bound to integrin $(34,52)$. There are several possible explanations for low occupancy including steric hindrance, owing to the large size of the integrin molecules, and nonphysiological binding conditions. Together, the conformational heterogeneity and the low occupancy effectively abolish much of the integrin density when averaging approaches are used, as has been observed for viral spikes and virus-antibody and virus-receptor complexes $(6,37,52,77)$. We have previously used classification analysis and vertex reconstruction to sort out such variation, but this was precluded here because of the size of the integrin with respect to the capsid $(14,36,37,40)$. Modeling of the HPEV1-integrin interactions 
allowed between 20 and 60 integrin molecules per capsid, depending on the orientations of the molecules relative to the binding sites. Thus, the effect of steric hindrance depends on the degree of rotational freedom allowed for the integrin molecules. A full complement of integrin molecules is not necessarily required for infection; e.g., only one receptor molecule needs to bind to parvovirus for infection to commence (29).

In conclusion, we have solved the structure of the previously uncharacterized HPEV1 to $0.85-\mathrm{nm}$ resolution and studied the binding of two integrins to the virus. We found that the binding of both integrins involves the RGD loop located in VP1 and that soluble $\alpha_{V} \beta_{6}$ is a high-affinity receptor for HPEV1 whereas $\alpha_{V} \beta_{3}$ exhibits lower affinity. Finally, our data indicate that under the conditions studied, neither species of integrin promotes uncoating so additional steps are most likely required in vivo.

\section{ACKNOWLEDGMENTS}

We thank Dean Sheppard for the $\alpha_{\mathrm{V}} \beta_{6}$-expressing cell line, Ritva Kajander for excellent technical assistance, the Electron Microscopy Unit, Institute of Biotechnology, Helsinki University, for providing facilities, and the CSC-IT Center for Science, Ltd., for providing computational resources.

This work was supported by the Academy of Finland Centre of Excellence Programme in Virus Research (2006 to 2011; 1129684 to S.J.B.), Sigrid Juselius Foundation (S.J.B. and T.H.), and the Academy of Finland (128539 to P.S. and 122215 to T.H.). R.S.S. thanks Timothy $\mathrm{S}$. Baker both for encouraging this collaboration and supporting the work through his NIH grants R37 GM-033050 and R01 AI-079095 and gift from the Agouron Foundation. J.S. is a Ph.D. fellow of the National Graduate School in Informational and Structural Biology; O.H. is a Ph.D. fellow of Turku Graduate School of Biomedical Sciences.

J.S., P.S., S.J.B., and T.H. designed the experiments, P.S. and O.H. purified reagents and carried out affinity assays, and J.S., P.L., and R.S.S. carried out EM and image reconstruction; all authors contributed to interpretation of the results and wrote the manuscript.

\section{REFERENCES}

1. Abed, Y., and G. Boivin. 2005. Molecular characterization of a Canadian human parechovirus (HPeV)-3 isolate and its relationship to other HPeVs. J. Med. Virol. 77:566-570.

2. Abraham, G., and R. J. Colonno. 1984. Many rhinovirus serotypes share the same cellular receptor. J. Virol. 51:340-345.

3. Acharya, R., E. Fry, D. Stuart, G. Fox, D. Rowlands, and F. Brown. 1989. The three-dimensional structure of foot-and-mouth disease virus at $2.9 \AA$ resolution. Nature 337:709-716.

4. Al-Sunaidi, M., C. H. Williams, P. J. Hughes, D. P. Schnurr, and G. Stanway. 2007. Analysis of a new human parechovirus allows the definition of parechovirus types and the identification of RNA structural domains. J. Virol. 81:1013-1021.

5. Arita, M., S. Koike, J. Aoki, H. Horie, and A. Nomoto. 1998. Interaction of poliovirus with its purified receptor and conformational alteration in the virion. J. Virol. 72:3578-3586.

6. Baker, T. S., N. H. Olson, and S. D. Fuller. 1999. Adding the third dimension to virus life cycles: three-dimensional reconstruction of icosahedral viruses from cryo-electron micrographs. Microbiol. Mol. Biol. Rev. 63:862-922.

7. Bennett-Lovsey, R. M., A. D. Herbert, M. J. Sternberg, and L. A. Kelley 2008. Exploring the extremes of sequence/structure space with ensemble fold recognition in the program Phyre. Proteins 70:611-625.

8. Benschop, K. S., J. Schinkel, M. E. Luken, P. J. van den Broek, M. F Beersma, N. Menelik, H. W. van Eijk, H. L. Zaaijer, C. M. VandenBrouckeGrauls, M. G. Beld, and K. C. Wolthers. 2006. Fourth human parechovirus serotype. Emerg. Infect. Dis. 12:1572-1575.

9. Bhella, D., I. G. Goodfellow, P. Roversi, D. Pettigrew, Y. Chaudhry, D. J. Evans, and S. M. Lea. 2004. The structure of echovirus type 12 bound to a two-domain fragment of its cellular attachment protein decay-accelerating factor (CD 55). J. Biol. Chem. 279:8325-8332.

10. Boivin, G., Y. Abed, and F. D. Boucher. 2005. Human parechovirus 3 and neonatal infections. Emerg. Infect. Dis. 11:103-105.

11. Boonyakiat, Y., P. J. Hughes, F. Ghazi, and G. Stanway. 2001. Arginineglycine-aspartic acid motif is critical for human parechovirus 1 entry. J. Virol 75:10000-10004.
12. Bowman, V. D., E. S. Chase, A. W. Franz, P. R. Chipman, X. Zhang, K. L. Perry, T. S. Baker, and T. J. Smith. 2002. An antibody to the putative aphid recognition site on cucumber mosaic virus recognizes pentons but not hexons. J. Virol. 76:12250-12258.

13. Brabec, M., G. Baravalle, D. Blaas, and R. Fuchs. 2003. Conformational changes, plasma membrane penetration, and infection by human rhinovirus type 2: role of receptors and low pH. J. Virol. 77:5370-5377.

14. Briggs, J. A., J. T. Huiskonen, K. V. Fernando, R. J. Gilbert, P. Scotti, S. J. Butcher, and S. D. Fuller. 2005. Classification and three-dimensional reconstruction of unevenly distributed or symmetry mismatched features of icosahedral particles. J. Struct. Biol. 150:332-339.

15. Brown, B., M. S. Oberste, K. Maher, and M. A. Pallansch. 2003. Complete genomic sequencing shows that polioviruses and members of human enterovirus species $\mathrm{C}$ are closely related in the noncapsid coding region. J. Virol. 77:8973-8984.

16. Bubeck, D., D. J. Filman, N. Cheng, A. C. Steven, J. M. Hogle, and D. M. Belnap. 2005. The structure of the poliovirus $135 \mathrm{~S}$ cell entry intermediate at $10 \AA$ resolution reveals the location of an externalized polypeptide that binds to membranes. J. Virol. 79:7745-7755.

17. Chang, K. H., P. Auvinen, T. Hyypiä, and G. Stanway. 1989. The nucleotide sequence of coxsackievirus A9; implications for receptor binding and enterovirus classification. J. Gen. Virol. 70:3269-3280.

18. Denis, P., H. D. Liebig, N. Nowotny, C. Billinis, O. Papadopoulos, R. S. O'Hara, N. J. Knowles, and F. Koenen. 2006. Genetic variability of encephalomyocarditis virus (EMCV) isolates. Vet. Microbiol. 113:1-12.

19. Drexler, J. F., K. Grywna, A. Stocker, P. S. Almeida, T. C. Medrado-Ribeiro, M. Eschbach-Bludau, N. Petersen, H. da Costa Ribeiro, Jr., and C. Drosten. 2009. Novel human parechovirus from Brazil. Emerg. Infect. Dis. 15:310 313.

20. Ehrnst, A., and M. Eriksson. 1993. Epidemiological features of type 22 echovirus infection. Scand. J. Infect. Dis. 25:275-281.

21. Filman, D. J., M. W. Wien, J. A. Cunningham, J. M. Bergelson, and J. M. Hogle. 1998. Structure determination of echovirus 1. Acta Crystallogr. D Biol. Crystallogr. 54:1261-1272.

22. Fricks, C. E., and J. M. Hogle. 1990. Cell-induced conformational change in poliovirus: externalization of the amino terminus of VP1 is responsible for liposome binding. J. Virol. 64:1934-1945.

23. Fry, E. E., S. M. Lea, T. Jackson, J. W. Newman, F. M. Ellard, W. E. Blakemore, R. Abu-Ghazaleh, A. Samuel, A. M. King, and D. I. Stuart. 1999. The structure and function of a foot-and-mouth disease virus-oligosaccharide receptor complex. EMBO J. 18:543-554.

24. Ghazi, F., P. J. Hughes, T. Hyypiä, and G. Stanway. 1998. Molecular analysis of human parechovirus type 2 (formerly echovirus 23). J. Gen. Virol. 79: 2641-2650.

25. Gouet, P., X. Robert, and E. Courcelle. 2003. ESPript/ENDscript: extracting and rendering sequence and $3 \mathrm{D}$ information from atomic structures of proteins. Nucleic Acids Res. 31:3320-3323.

26. Grant, R. A., D. J. Filman, R. S. Fujinami, J. P. Icenogle, and J. M. Hogle. 1992. Three-dimensional structure of Theiler virus. Proc. Natl. Acad. Sci. U. S. A. 89:2061-2065.

27. Greve, J. M., C. P. Forte, C. W. Marlor, A. M. Meyer, H. Hoover-Litty, D. Wunderlich, and A. McClelland. 1991. Mechanisms of receptor-mediated rhinovirus neutralization defined by two soluble forms of ICAM-1. J. Virol 65:6015-6023.

28. Grist, N. R., E. J. Bell, and F. Assaad. 1978. Enteroviruses in human disease. Prog. Med. Virol. 24:114-157.

29. Hafenstein, S., L. M. Palermo, V. A. Kostyuchenko, C. Xiao, M. C. Morais, C. D. Nelson, V. D. Bowman, A. J. Battisti, P. R. Chipman, C. R. Parrish, and M. G. Rossmann. 2007. Asymmetric binding of transferrin receptor to parvovirus capsids. Proc. Natl. Acad. Sci. U. S. A. 104:6585-6589.

30. Harvala, H., and P. Simmonds. 2009. Human parechoviruses: biology, epidemiology and clinical significance. J. Clin. Virol. 45:1-9.

31. He, Y., V. D. Bowman, S. Mueller, C. M. Bator, J. Bella, X. Peng, T. S. Baker, E. Wimmer, R. J. Kuhn, and M. G. Rossmann. 2000. Interaction of the poliovirus receptor with poliovirus. Proc. Natl. Acad. Sci. U. S. A. 97:79-84.

32. He, Y., P. R. Chipman, J. Howitt, C. M. Bator, M. A. Whitt, T. S. Baker, R. J. Kuhn, C. W. Anderson, P. Freimuth, and M. G. Rossmann. 2001. Interaction of coxsackievirus B3 with the full length coxsackievirus-adenovirus receptor. Nat. Struct. Biol. 8:874-878.

33. Heikkilä, O., P. Susi, G. Stanway, and T. Hyypiä. 2009. Integrin $\alpha_{V} \beta_{6}$ is a high-affinity receptor for coxsackievirus A9. J. Gen. Virol. 90:197-204.

34. Hendry, E., H. Hatanaka, E. Fry, M. Smyth, J. Tate, G. Stanway, J. Santti, M. Maaronen, T. Hyypiä, and D. Stuart. 1999. The crystal structure of coxsackievirus A9: new insights into the uncoating mechanisms of enteroviruses. Structure 7:1527-1538.

35. Hogle, J. M., M. Chow, and D. J. Filman. 1985. Three-dimensional structure of poliovirus at $2.9 \AA$ resolution. Science 229:1358-1365.

36. Huiskonen, J. T., H. T. Jäälinoja, J. A. Briggs, S. D. Fuller, and S. J. Butcher. 2007. Structure of a hexameric RNA packaging motor in a viral polymerase complex. J. Struct. Biol. 158:156-164.

37. Huiskonen, J. T., V. Manole, and S. J. Butcher. 2007. Tale of two spikes in bacteriophage PRD1. Proc. Natl. Acad. Sci. U. S. A. 104:6666-6671. 
38. Hyypiä, T., C. Horsnell, M. Maaronen, M. Khan, N. Kalkkinen, P. Auvinen, L. Kinnunen, and G. Stanway. 1992. A distinct picornavirus group identified by sequence analysis. Proc. Natl. Acad. Sci. U. S. A. 89:8847-8851.

39. Ito, M., T. Yamashita, H. Tsuzuki, N. Takeda, and K. Sakae. 2004. Isolation and identification of a novel human parechovirus. J. Gen. Virol. 85:391-398

40. Jäälinoja, H. T., E. Roine, P. Laurinmäki, H. M. Kivela, D. H. Bamford, and S. J. Butcher. 2008. Structure and host-cell interaction of SH1, a membranecontaining, halophilic euryarchaeal virus. Proc. Natl. Acad. Sci. U. S. A. 105:8008-8013.

41. Johansson, S., B. Niklasson, J. Maizel, A. E. Gorbalenya, and A. M. Lindberg. 2002. Molecular analysis of three Ljungan virus isolates reveals a new, close-to-root lineage of the Picornaviridae with a cluster of two unrelated $2 \mathrm{~A}$ proteins. J. Virol. 76:8920-8930.

42. Joki-Korpela, P., and T. Hyypiä. 1998. Diagnosis and epidemiology of echovirus 22 infections. Clin. Infect. Dis. 27:129-136.

43. Joki-Korpela, P., V. Marjomäki, C. Krogerus, J. Heino, and T. Hyypiä. 2001 Entry of human parechovirus 1. J. Virol. 75:1958-1967.

44. Kim, S. S., T. J. Smith, M. S. Chapman, M. C. Rossmann, D. C. Pevear, F. J. Dutko, P. J. Felock, G. D. Diana, and M. A. McKinlay. 1989. Crystal structure of human rhinovirus serotype 1A (HRV1A). J. Mol. Biol. 210:91-111.

45. Kivioja, T., J. Ravantti, A. Verkhovsky, E. Ukkonen, and D. Bamford. 2000 Local average intensity-based method for identifying spherical particles in electron micrographs. J. Struct. Biol. 131:126-134.

46. Klump, W. M., I. Bergmann, B. C. Muller, D. Ameis, and R. Kandolf. 1990 Complete nucleotide sequence of infectious coxsackievirus B3 cDNA: two initial 5' uridine residues are regained during plus-strand RNA synthesis. J. Virol. 64:1573-1583

47. Kolatkar, P. R., J. Bella, N. H. Olson, C. M. Bator, T. S. Baker, and M. G. Rossmann. 1999. Structural studies of two rhinovirus serotypes complexed with fragments of their cellular receptor. EMBO J. 18:6249-6259.

48. Kremer, J. R., D. N. Mastronarde, and J. R. McIntosh. 1996. Computer visualization of three-dimensional image data using IMOD. J. Struct. Biol. 116:71-76

49. Kurz, C., S. Forss, H. Kupper, K. Strohmaier, and H. Schaller. 1981. Nucleotide sequence and corresponding amino acid sequence of the gene for the major antigen of foot and mouth disease virus. Nucleic Acids Res. 9:1919-1931

50. Larkin, M. A., G. Blackshields, N. P. Brown, R. Chenna, P. A. McGettigan, H. McWilliam, F. Valentin, I. M. Wallace, A. Wilm, R. Lopez, J. D. Thompson, T. J. Gibson, and D. G. Higgins. 2007. Clustal W and Clustal X version 2.0. Bioinformatics 23:2947-2948.

51. Li, L., J. Victoria, A. Kapoor, A. Naeem, S. Shaukat, S. Sharif, M. M. Alam, M. Angez, S. Z. Zaidi, and E. Delwart. 2009. Genomic characterization of novel human parechovirus type. Emerg. Infect. Dis. 15:288-291.

52. Lindert, S., M. Silvestry, T. M. Mullen, G. R. Nemerow, and P. L. Stewart 2009. Cryo-electron microscopy structure of an adenovirus-integrin complex indicates conformational changes in both penton base and integrin. J. Virol. 83:11491-11501.

53. Ludtke, S. J., P. R. Baldwin, and W. Chiu. 1999. EMAN: semiautomated software for high-resolution single-particle reconstructions. J. Struct. Biol. 128:82-97.

54. Mastronarde, D. N. 2005. Automated electron microscope tomography using robust prediction of specimen movements. J. Struct. Biol. 152:36-51.

55. Mastronarde, D. N. 1997. Dual-axis tomography: an approach with alignment methods that preserve resolution. J. Struct. Biol. 120:343-352.

56. Mindell, J. A., and N. Grigorieff. 2003. Accurate determination of loca defocus and specimen tilt in electron microscopy. J. Struct. Biol. 142:334 347.

57. Muckelbauer, J. K., M. Kremer, I. Minor, L. Tong, A. Zlotnick, J. E. Johnson, and M. G. Rossmann. 1995. Structure determination of coxsackievirus $\mathrm{B} 3$ to $3.5 \AA$ A resolution. Acta Crystallogr. D Biol. Crystallogr. 51:871-887.

58. Oberste, M. S., K. Maher, and M. A. Pallansch. 1998. Complete sequence of echovirus 23 and its relationship to echovirus 22 and other human enteroviruses. Virus Res. 56:217-223.

59. Parry, N., G. Fox, D. Rowlands, F. Brown, E. Fry, R. Acharya, D. Logan, and D. Stuart. 1990. Structural and serological evidence for a novel mechanism of antigenic variation in foot-and-mouth disease virus. Nature 347:569-572.

60. Pettersen, E. F., T. D. Goddard, C. C. Huang, G. S. Couch, D. M. Greenblatt, E. C. Meng, and T. E. Ferrin. 2004. UCSF Chimera-a visualization system for exploratory research and analysis. J. Comput. Chem. 25:1605-1612.

61. Prchla, E., E. Kuechler, D. Blaas, and R. Fuchs. 1994. Uncoating of human rhinovirus serotype 2 from late endosomes. J. Virol. 68:3713-3723.

62. Pulli, T., E. Koivunen, and T. Hyypiä. 1997. Cell-surface interactions of echovirus 22. J. Biol. Chem. 272:21176-21180.

63. Racaniello, V. R., and D. Baltimore. 1981. Molecular cloning of poliovirus cDNA and determination of the complete nucleotide sequence of the viral genome. Proc. Natl. Acad. Sci. U. S. A. 78:4887-4891.

64. Roivainen, M., T. Hyypiä, L. Piirainen, N. Kalkkinen, G. Stanway, and T. Hovi. 1991. RGD-dependent entry of coxsackievirus A9 into host cells and its bypass after cleavage of VP1 protein by intestinal proteases. J. Virol. 65: 4735-4740.

65. Rossmann, M. G., E. Arnold, J. W. Erickson, E. A. Frankenberger, J. P. Griffith, H. J. Hecht, J. E. Johnson, G. Kamer, M. Luo, A. G. Mosser, et al. 1985. Structure of a human common cold virus and functional relationship to other picornaviruses. Nature 317:145-153.

66. Sarachu, M., and M. Colet. 2005. wEMBOSS: a web interface for EMBOSS. Bioinformatics 21:540-541.

67. Schober, D., P. Kronenberger, E. Prchla, D. Blaas, and R. Fuchs. 1998. Major and minor receptor group human rhinoviruses penetrate from endosomes by different mechanisms. J. Virol. 72:1354-1364.

68. Smyth, M., J. Tate, E. Hoey, C. Lyons, S. Martin, and D. Stuart. 1995 Implications for viral uncoating from the structure of bovine enterovirus. Nat. Struct. Biol. 2:224-231.

69. Stanway, G., P. J. Hughes, R. C. Mountford, P. D. Minor, and J. W. Almond. 1984. The complete nucleotide sequence of a common cold virus: human rhinovirus 14. Nucleic Acids Res. 12:7859-7875.

70. Stanway, G., and T. Hyypiä. 1999. Parechoviruses. J. Virol. 73:5249-5254.

71. Stanway, G., N. Kalkkinen, M. Roivainen, F. Ghazi, M. Khan, M. Smyth, O. Meurman, and T. Hyypiä. 1994. Molecular and biological characteristics of echovirus 22, a representative of a new picornavirus group. J. Virol. 68:82328238 .

72. Stuart, A. D., T. A. McKee, P. A. Williams, C. Harley, S. Shen, D. I. Stuart, T. D. Brown, and S. M. Lea. 2002. Determination of the structure of a decay accelerating factor-binding clinical isolate of echovirus 11 allows mapping of mutants with altered receptor requirements for infection. J. Virol. 76:76947704.

73. Tauriainen, S., M. Martiskainen, S. Oikarinen, M. Lönnrot, H. Viskari, J. Ilonen, O. Simell, M. Knip, and H. Hyöty. 2007. Human parechovirus 1 infections in young children-no association with type 1 diabetes. J. Med. Virol. 79:457-462.

74. Triantafilou, K., M. Triantafilou, Y. Takada, and N. Fernandez. 2000. Human parechovirus 1 utilizes integrins $\alpha_{v} \beta_{3}$ and $\alpha_{v} \beta_{1}$ as receptors. J. Virol. 74:5856-5862.

75. van Heel, M., and G. Harauz. 1986. Resolution criteria for three dimensional reconstruction. Optik 73:119-122.

76. van Heel, M., and M. Schatz. 2005. Fourier shell correlation threshold criteria. J. Struct. Biol. 151:250-262.

77. Waddington, S. N., J. H. McVey, D. Bhella, A. L. Parker, K. Barker, H. Atoda, R. Pink, S. M. Buckley, J. A. Greig, L. Denby, J. Custers, T. Morita, I. M. Francischetti, R. Q. Monteiro, D. H. Barouch, N. van Rooijen, C. Napoli, M. J. Havenga, S. A. Nicklin, and A. H. Baker. 2008. Adenovirus serotype 5 hexon mediates liver gene transfer. Cell 132:397-409.

78. Watanabe, K., M. Oie, M. Higuchi, M. Nishikawa, and M. Fujii. 2007. Isolation and characterization of novel human parechovirus from clinical samples. Emerg. Infect. Dis. 13:889-895.

79. Weinacker, A., A. Chen, M. Agrez, R. I. Cone, S. Nishimura, E. Wayner, R. Pytela, and D. Sheppard. 1994. Role of the integrin $\alpha_{v} \beta_{6}$ in cell attachment to fibronectin. Heterologous expression of intact and secreted forms of the receptor. J. Biol. Chem. 269:6940-6948.

80. Wigand, R., and A. B. Sabin. 1961. Properties of ECHO types 22, 23 and 24 viruses. Arch. Gesamte Virusforsch. 11:224-247.

81. Williams, C. H., T. Kajander, T. Hyypiä, T. Jackson, D. Sheppard, and G. Stanway. 2004. Integrin $\alpha_{\mathrm{v}} \beta_{6}$ is an RGD-dependent receptor for coxsackievirus A9. J. Virol. 78:6967-6973.

82. Wu, S., J. Skolnick, and Y. Zhang. 2007. Ab initio modeling of small proteins by iterative TASSER simulations. BMC Biol. 5:17.

83. Xiao, C., C. M. Bator-Kelly, E. Rieder, P. R. Chipman, A. Craig, R. J. Kuhn, E. Wimmer, and M. G. Rossmann. 2005. The crystal structure of coxsackievirus A21 and its interaction with ICAM-1. Structure 13:1019-1033.

84. Xiong, J. P., T. Stehle, R. Zhang, A. Joachimiak, M. Frech, S. L. Goodman, and M. A. Arnaout. 2002. Crystal structure of the extracellular segment of integrin $\alpha_{\mathrm{v}} \beta_{3}$ in complex with an Arg-Gly-Asp ligand. Science 296:151-155.

85. Yan, X., K. A. Dryden, J. Tang, and T. S. Baker. 2007. Ab initio random model method facilitates 3D reconstruction of icosahedral particles. J. Struct. Biol. 157:211-225.

86. Yan, X., R. S. Sinkovits, and T. S. Baker. 2007. AUTO3DEM-an automated and high throughput program for image reconstruction of icosahedral particles. J. Struct. Biol. 157:73-82.

87. Zhang, X., S. B. Walker, P. R. Chipman, M. L. Nibert, and T. S. Baker. 2003. Reovirus polymerase lambda 3 localized by cryo-electron microscopy of virions at a resolution of 7.6 A. Nat. Struct. Biol. 10:1011-1018.

88. Zhang, Y. 2008. I-TASSER server for protein 3D structure prediction. BMC Bioinformatics 9:40.

89. Zhang, Y. 2007. Template-based modeling and free modeling by I-TASSER in CASP7. Proteins 69:108-117.

90. Zimmermann, H., H. J. Eggers, and B. Nelsen-Salz. 1996. Molecular cloning and sequence determination of the complete genome of the virulent echovirus 9 strain Barty. Virus Genes 12:149-154. 